\title{
The Effect of "Brexit" Uncertainty on The FTSE 100 Index and The UK Pound
}

\author{
Rory McCann and Daniel Broby $(\bowtie)$ \\ Centre for Financial Regulation and Innovation, Strathclyde University, Glasgow, United Kingdom \\ daniel.brobyestrath.ac.uk
}

\section{ABSTRACT}

We investigate the impact of the uncertainty surrounding the United Kingdom's proposed departure from the European Community ("Brexit") on financial assets. We conduct an event study around the November 14th 2018 draft withdrawal agreement. Our motivation was that the economic impact of the various political permutations that persisted throughout the negotiation period were both measurable and distinct. The probability of each Brexit scenario that was discussed varied over the political discourse. Using opinion poll data we investigate the event impact on both the FTSE 100 and the UK Pound. We found that, in accordance with existing academic evidence, asset prices discounted the weighted probabilistic economic impact of likely outcomes. We observe, however, that this impact was not as immediate as theory suggests. Interestingly, currency markets had the greater sensitivity. Our conclusions have important implications for the pricing of country risk premia in general and the European Union in particular. Key takeaways: 1) Asset prices were slow to discount the weighted probabilistic economic impact of Brexit risk. 2) Currency markets had the greater sensitivity to changes in Brexit risk. 3) Country risk premia can be impacted by perceived changes in custom union.

Keywords: Brexit, event study, EU referendum, risk, investor sentiment, market efficiency, country Risk JEL Classification G10, G11, G12, G14

Cite this article as: McCann, R., Broby, D. (2021). The Effect of "Brexit" Uncertainty on The FTSE 100 Index and The UK Pound. European Journal of Economics, 1(1), 1-13. https://doi.org/10.33422/eje.v1i1.42

\section{Introduction}

Asset prices and risk premia are commonly believed to react to new information. We investigate this in the context of the impact of opinion changes on risk premia during the uncertainty surrounding the United Kingdom's membership of the European Union (EU). A referendum on its membership was conducted on $23^{\text {rd }}$ June 2016. The result of the vote was considered a shock by most commentators, with some $51.9 \%$ in favour of leaving. The twoyear withdrawal process, initiated on $29^{\text {th }}$ March 2017, and subsequently extended, proved politically fraught due to the frictions between the public, parliament and the political parties who were likewise divided. The slow and tortuous process, hereafter referred to as "Brexit", dominated political and economic commentary in the United Kingdom. It had a measurable impact on the pricing of securities in the FTSE 100 and the Pound using the Stirling currency cross rates. We investigate this and our findings have important implications for the pricing of political risk in the face of uncertainty.

According to Hobolt (2016), the outcome of the Brexit referendum, a mandate to the government to leave the common market, represents a risk to the political establishment across Europe. Kierzwnkowski et al (2016) claim it also represents a risk to both British and European 
economies with potential repercussions to other OECD countries. The uncertainty and political dislocation represent an economic shock that is transmitted both in the precursor to the event as well as in its aftermath. Broby (2000) shows that political uncertainty in the UK can manifest itself in specific election related risk premia. We use an event study to isolate Brexit sentiment changes in both the UK equity and currency markets.

Our investigation has economic relevance. Political uncertainty can impact consumer and business confidence. The effects stem from the potential and real impact of trade tariffs, red tape and the curtailment of the freedom of labour. These in turn impact wealth and the level of asset prices. The societal implications justify research into their effects. Our contribution is in decomposing the political risk factor over a continuous event time horizon using smoothed opinion poll data. We identify a Brexit risk premia which we show to be inefficient in its incorporation into market pricing.

\section{Background to Brexit}

The decision by the United Kingdom to leave the European Union represented a major reversal in the expansion of the free trade in goods and services in the region. The only prior precedent was the decision by Greenland to leave the former European Economic Community. It is noted, however, that Greenland maintained close ties with Denmark and the common market. The size and integrated nature of the United Kingdom made Brexit into an economically influential process and it warrants investigation as potentially other European Union countries could consider withdrawal at some point. It also resulted in a reassessment of party politics in the Britain, fundamentally changing the two-party system with the subsequent rise of the Brexit party.

The European Union is the United Kingdom's largest trading partner. Dinghra et al (2017), in their analysis of the cost benefits of Brexit, show that over 50\% of the United Kingdom's imports and $45 \%$ of its exports are related to the common market. The trading of goods and services made the Stirling-Euro and Stirling-Dollar cross rates very sensitive, as shown in Figure 1. Equity prices were also sensitive, but to a lesser degree.

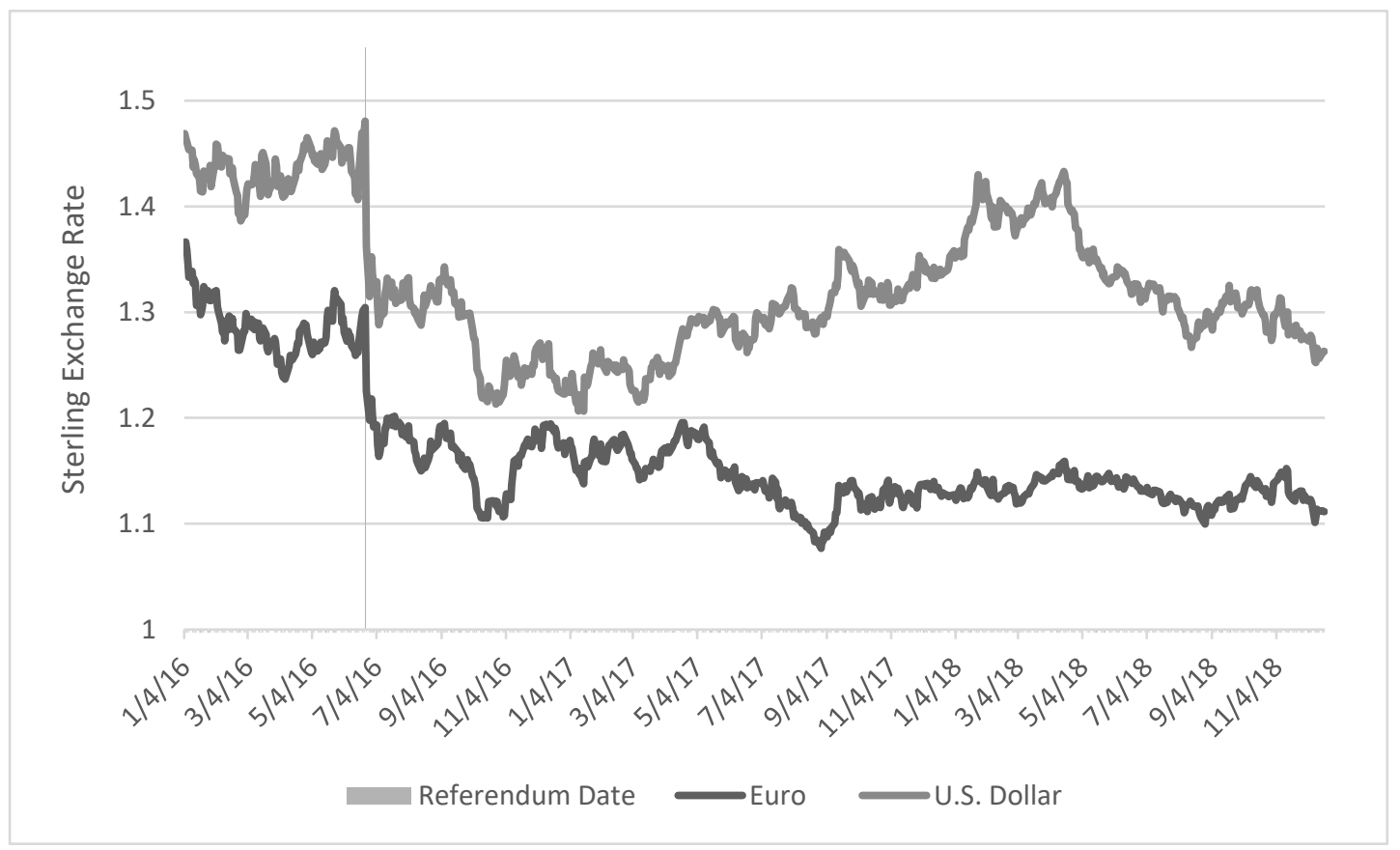

Figure 1. This graph represents the Stirling Euro and dollar cross rates for the full sample period, with the exogenous shock of the referendum highlighted. It is worth noting that while Stirling fell after the referendum, share prices recovered. Stirling values did not return to their pre-referendum values. 
Davies and Studnicka (2018) analysed the cross section of these changes, finding that large capitalization companies were more sensitive than small. They found the market reaction was proportionate to the supply side economic shock. Ramiah, Pham, and Moosa (2017) further decomposed the impact on equity markets. They drilled down into sectors and found that the financial sector was hardest hit, with all sectors impacted negatively.

The results of the referendum represent an exogenous shock. The initial expectations were that there would be several rounds of discussion and then ratification by parliament. The formal notification under Article 50 was given despite their being no clear roadmap. The assumption was made that the default in the event of no agreement would be adoption of the rules of the World Trade Organisation. The failure to reach a consensus agreement during the two-year notification period contributed to the uncertainty and the Brexit risk premia changed with sentiment. The uncertainty was reflected in changing public opinion towards Brexit, as demonstrated in Figure 2 which highlights our event study date with a vertical line transecting the opinions or respondents.

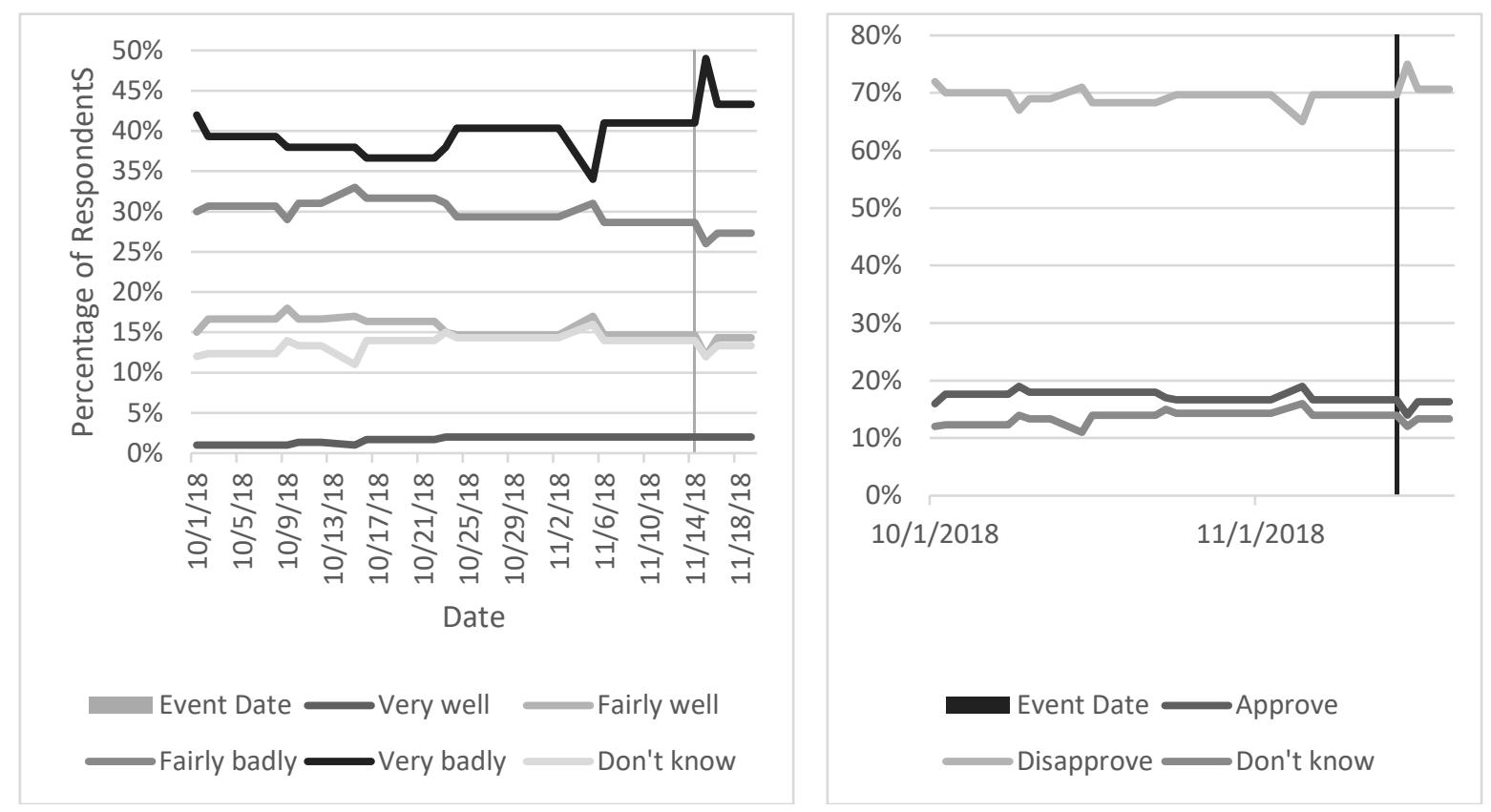

Figure 2. Opinion Poll Responses. The first graph shows the response percentages for the opinion poll results of expected impact of Brexit over the estimation and event period, with the event date highlighted by the vertical line. The second graph shows the poll data based on approve and disapprove. It has been combined so that positive responses (very well and fairly well) and negative responses (fairly badly and very badly) have been merged into singular variables.

The initial pre-referendum analysis, such as that by Bush and Matthes (2016), warned that the GDP impact of Brexit would be between $1 \%$ and $5 \%$. Subsequently, more estimates were made, all with negative economic consequences. Dinghra et al (2017), mentioned earlier, used a general equilibrium model to forecast different Brexit outcomes. They foresaw declines in average income per capita of between $6.3 \%$ and $9.4 \%$ based on two scenarios, a Norway like deal (soft Brexit), and a World Trade Organization deal (hard Brexit). The Treasury's own forecast, which included a third option which envisioned a comprehensive free trade agreement along the lines on the one with Canada. It evaluated the impact on GDP over a fifteen-year time horizon. We refer to these three possibilities as scenario one, two and three respectively and model these using a GDP to stock ratio. We use the three scenarios in combination with opinion poll data to quantify the impact of changing Brexit risk premia. 


\subsection{Literature}

Much of the literature of political risk focuses on expropriation and change of governments. There is far less on the effects of customs union, the benefits of which were exposed by Viner (1950). He suggests the impact is largely positive. This would suggest the impact of leaving is negative. Krueger (1997) expands on the distinction between Free Trade Areas and customs unions, arguing that a customs union is always Pareto optimal. Supporting this, Baier and F (2007) quantified the impact of bilateral trade agreements, demonstrating that mutual trade can double within a decade. There is no literature on whether the reverse is true, but we contend that it is reasonable to infer there would be a negative trade related impact.

Theory suggests that the economic implications of Brexit should be discounted in security prices. In an efficient market, prices adjust rapidly to new information as demonstrated by numerous authors including Fama et al (1969). With political information, we observe, in the spirit of Fama (1991) that market efficiency and equilibrium pricing are inseparable. As such, the focus of this paper is on the cross section of the expected returns based on the probabilistic prediction of the various Brexit out-comes.

In the broader literature on political discourse, there has been much academic investigation into political events. These are nicely summed up in Kobrin (1979) in his review and reconsideration of political risk. It can be seen, from such an evaluation, that Brexit provides an additional level of uncertainty, namely the date and terms of the outcome. The uncertainty stems from policy decisions motivated by both economic and non-economic objectives. The costs associated with these decisions and uncertainty about future actions both result in asset price changes.

The uncertainties are further exaggerated because Brexit is what DeSio et al (2016) would term a low yield issue. In other words, an issue on which a political party does not gain advantage when its members are divided. Indeed, as it turned out, Brexit proved a negative yield issue. Pastor and Veronesi (2102) investigated political uncertainty and the pricing of securities. They found that securities typically fell on the announcement of a policy change. They also found that the magnitude of this decline and the jump in the risk premium was greater if there was greater uncertainty about government policy. Pastor and Veronesi (2013) went on to further point out that this makes securities more volatile and more correlated. This uncertainty, they argue, stems from the possible policy shocks which are to some extent orthogonal to economic shocks.

Isolating political risk from other risk factors has presented challenges to prior researchers. One approach to identify such a risk premia is to investigate the variation of security price returns around elections. Kelly et all (2016) pursued such an approach in the options market, finding that political uncertainty is priced into such instruments. Another approach, as exampled by Gemmill (1992), is to test around opinion polls. We take the latter approach so as to capture a simple risk premia, reflecting the time varying nature of Brexit sentiment during our sample period.

Our enquiry builds on the work of a number of academics, including Leblang and Mukherjee (2005), and Białkowski et al (2008), that have examined elections and the resulting volatility. The broad consensus of these studies is that narrower the result of an election, the greater the market volatility. We suggest this is an intuitive result as greater uncertainty typically results in asset price volatility. We also observe that the opinion polls during our sample period were close to evenly divided when taking into account the margin of error. The way thinking is impacted by surveys, as identified by Ansolabegere and Schaffner (2014), make the measurement error particularly pertinent in this case.

The link between GDP and equity returns has been the subject of much academic investigation. We refer to Hassapis and Kalyvitis (2002), who show a significant causal relationship in the 
United Kingdom based on Vector Autoregressions and Granger causality tests. The findings of Dhingra et al (2016) suggest that the UK impact is larger than all other EU countries combined. On the currency side, Schiavo, (2008) investigated the correlation and endogeneity of currency areas, providing evidence that economic integration exerts a positive effect on output. After Mundell (1968), we observe that tariff preferences and terms of trade are variables that affect exchange rates. We find this linkage in the movements of the Stirling cross rates. The observed reaction of asset markets, controlled for exogenous news flow, therefore represents a change in the Brexit risk premia. We view the Brexit risk premia as a subset of country risk premia.

\subsection{Market data}

We used daily stock returns from Bloomberg based on the constituents of the FTSE 100, from the $1^{\text {st }}$ of January 2016 to the $2^{\text {nd }}$ of January 2019. The dataset comprises 41 sectors, the constituents of which were taken from the London Stock Exchange's website.

The FTSE 100 was chosen as it is the main indices in the United Kingdom and therefore arguably those that will be most impacted by Brexit. It represents the largest 100 companies by market capitalization. The FTSE 100 is generally seen to be market driven.

We cleaned the data for public holidays and excluded stocks that were not present in the index for the entire sample period. Daily returns were calculated using continuous compounding returns method ${ }^{1}$. Excess returns were then generated by subtracting the risk-free rate, our proxy being the a one-month UK treasury bill.

We used daily currency returns from Bloomberg, principally on the Euro to Sterling cross exchange rate from the $1^{\text {st }}$ of January 2016 to the $2^{\text {nd }}$ of January 2019. Five other major trading currency rates were used to increase the sample size of the study, the US, Canadian and Australian Dollars, the Swiss Franc and the Japanese Yen.

Examining the summary statistics, all currencies' peak values for 2018 are lower than that of the full sample, but all currencies except the Euro show effectively consistent averages between 2018 and the whole sample period. This suggests that in 2018 Stirling was particularly weak against the Euro when compared to its performance against other currencies. We suggest this is potentially due in part to the Brexit process.

Opinion poll data was sourced from WhatEUThinks, a site maintained by NatCen Social Research. The data comprised of aggregated polls related to Brexit. The polls used were from YouGov that asked the question: "How well or badly do you think the government are doing at negotiating Britain's exit from the EU?". There were 76 polls conducted, with a frequency of approximately one every week. Summary statistics for the poll data can be seen in Table 1 .

Table 1.

Poll Summary Statistics

\begin{tabular}{lccccc}
\hline & Very well & Fairly well & Fairly badly & Very badly & Don't know \\
\hline Max & $2.0 \%$ & $21.0 \%$ & $35.0 \%$ & $49.0 \%$ & $16.0 \%$ \\
Min & $1.0 \%$ & $11.0 \%$ & $26.0 \%$ & $30.0 \%$ & $11.0 \%$ \\
Average & $1.4 \%$ & $15.7 \%$ & $30.4 \%$ & $39.6 \%$ & $13.1 \%$ \\
Std Dev & 0.0049 & 0.0272 & 0.0179 & 0.0445 & 0.0146 \\
\hline
\end{tabular}

Table 1. Summary statistics for the poll data from YouGov, responses to the question "How well or badly do you think the government are doing at negotiating Britain's exit from the EU?" Source: YouGov data. WhatEUThinks, a site maintained by NatCen Social Research.

The polling time series was not run as a daily poll, meaning the time series contained some gaps. The results have been smoothed to account for the missing periods using a three-way ${ }^{1} R_{i t}=\operatorname{Ln}\left(\frac{R I_{i t}}{R I_{i t-1}}\right)$ Where $R_{i t}$, the return for security $\mathrm{i}$ on day $\mathrm{t}$, is equal to the natural $\log$ of the return index value
today $R I_{i t}$, divided by the return index value on the preceding trading day $R I_{i t-1}$. 
moving average, creating a continuous set of data for the whole sample range. These were then aggregated so that responses were either approving or disapproving. We suggest this approach is appropriate for comparison with continuous financial market time series.

\section{Methodology}

Our dataset included a rich pool of testable events. In order to isolate the Brexit risk premia changes, we chose the draft withdrawal agreement as that proved to have the least noise in the surrounding period. This event involved an announcement that a Brexit deal had been reached between the UK Government and the European Union. It was announced in the afternoon of the $14^{\text {th }}$ of November 2018 . However, the following day the initially positive response was overshadowed by resistance from MPs from across the political spectrum. This resistance included several cabinet resignations and general doubt over the prospects of the deal being ratified by Parliament. This occurred on the first full day of trading after the announcement. As a result of this time differential, we selected the $15^{\text {th }}$ November as the event day and the event period from the $12^{\text {th }}$ to the $19^{\text {th }}$ of November.

We created values to reflect how GDP would likely change in each of three scenarios. These were detailed in an OECD report by Kierzenkowski et al (2016) (referred to as OECD henceforth), H.M. Treasury (2016) \& Dhingra et al (2016). These scenarios are then translated into stock price movements, labelled as scenario (1) No deal, (2) a Norway like deal and (3) a Canada like deal.

A Monte Carlo Simulation is used to create an average outcome from the range of uncertain possibilities in the three scenarios. In this case it will be used to analyse the impact of various deals on the economy, in several situations where each deal is more likely. This is made to reflect an announcement from the government of which deal they are pursuing, or new information becoming public which changes the likelihood of each outcome. In order to create variation in the simulation, upper and lower bounds are placed on the amount that stock prices are permitted to jump in a single period, in this case $1.5 \%$ either way. The results are shown in Figure 3.

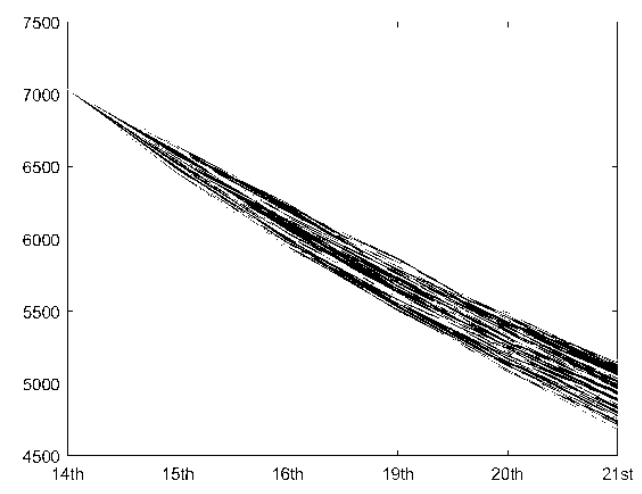

No Deal 

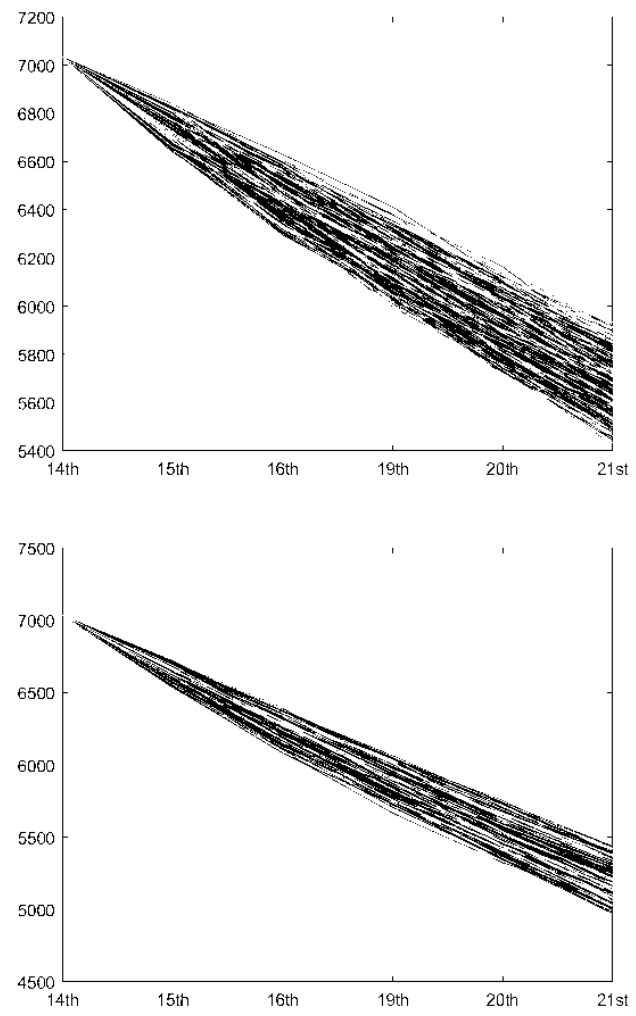

Norway

Canada

Figure 3. Monte Carlo outcomes of the three scenarios on the FTSE 100 Index. Figure 3 shows the output from the Monte Carlo simulation for the Treasury predictions. It uses the FTSE 100 value on the $14^{\text {th }}$ of November as a starting point. Each simulation is made up of 1,000 estimates.

The no deal scenario from the Monte Carlo analysis was clearly the worst outcome for the FTS 100. The Norwegian outcome gave the greatest uncertainty in terms of range of FTSE 100 predictions. We contend that our event period captures the impact from the announcement within two days following the event day. We consider it short enough to limit the likelihood of other news impacting on the market. Any noise from other events would reduce the effectiveness of the analysis and potentially weaken the results. In examining news reports from the surrounding days, we found no other major systemic events that were likely to have impacted financial markets.

The estimation period around the event was selected as the $1^{\text {st }}$ of October 2018 to the $9^{\text {th }}$ of November. This provides just over one month of data, with a total of thirty trading days. These days were used to estimate the expected returns for the event window. While many other studies utilise a longer estimation window, often of around 100 days or more as explained by Mackinlay, (1997), the decision was taken that this would be detrimental due to contamination from other related events. The EU summit in Salzburg was held on the $19^{\text {th }} \& 20^{\text {th }}$ of September, where European leaders provided a firmer than expected resistance to the UK Government's plans. This qualifies as a significant event which was not foreseen, and would bias the estimation window if included. We justify this based on Corrado \& Zivney (1992) who find that short estimation periods, of around the length used in this study, lead to only a very small reduction in test performance for $\mathrm{T}$-stats and non-parametric tests.

\section{Results}

We present our three economic scenarios in Table 2. We apply a GDP to stock ratio (Panel 1) in order to measure the Treasury (Panel 2), OECD (Panel 3), and Dhingra et al (Panel 4) 
impacts of the three scenarios. These show that whatever the scenario there was a negative expectation for UK GDP.

Table 2.

Deal Outcome Multipliers

\begin{tabular}{lc}
\hline Panel 1: GDP to Stock Ratio & \\
\hline UK GDP & Value \\
(Millions) & $£ 2,033,623$ \\
FTSE 350 Capitalisation & $£ 2,098,874$ \\
(Millions) & 0.9689 \\
GDP/ Stock Capitalisation Ratio & \\
\hline
\end{tabular}

Panel 2: Treasury Multiplier

\begin{tabular}{lccc}
\hline & Scenario 1 & Scenario 2 & Scenario 3 \\
\hline $\begin{array}{l}\text { Treasury impact value } \\
\text { Stock adjusted value }\end{array}$ & -7.5 & -3.8 & -6.2 \\
$\begin{array}{l}\text { 1- Stock Adjusted value } \\
\text { (Multiplier) }\end{array}$ & 0.9273325 & 0.9631818 & 0.939928282 \\
\hline
\end{tabular}

Panel 3: OECD Multiplier

\begin{tabular}{lccc}
\hline & Scenario 1 & Scenario 2 & Scenario 3 \\
\hline OECD impact value & -7.7 & -2.7 & -5.1 \\
Stock adjusted value & -7.46053 & -2.61603 & -4.94139 \\
$\begin{array}{l}\text { 1- Stock Adjusted value } \\
\text { (Multiplier) }\end{array}$ & 0.9253947 & 0.9738397 & 0.9505861 \\
\hline
\end{tabular}

Panel 4: Dhingra et al Multiplier:

\begin{tabular}{lccc}
\hline & Scenario 1 & Scenario 2 & Scenario 3 \\
\hline Dhingra et al impact value & -3.1 & -0.53 & -1.815 \\
Stock adjusted value & -3.00359 & -0.513517 & -1.7585535 \\
1- Stock Adjusted value & 96.99641 & 99.486483 & 98.241447 \\
(Multiplier) & & &
\end{tabular}

Table 2 shows the calculation of the GDP to stock market capitalisation ratio, and Panel 2 shows the deal outcome values and their multiplication with the GDP to stock capitalisation ratio.

While this event study has been referring to the date in question as the deal announcement, it should be recalled that the real reaction from the markets was in response to MP's reaction to the deal, which put the future of the agreement into doubt. Therefore, these results effectively show how the market reacted when the likelihood of a highly integrational deal decreased, and the probability of a disorderly exit such as a no deal situation increased. The percentage values of how much probability changed by is a highly subjective one, and so translating the change directly into the proportional likelihoods will not be attempted here.

Table 3.

Regression Summary Statistics

Panel 1: FTSE 100

\begin{tabular}{lcccc}
\hline & Max & Min & Average & Std Dev \\
\hline Alpha & 0.0054 & -0.0083 & -0.0001 & 0.0025 \\
Beta & 2.6314 & -1.0491 & 1.0621 & 0.6168 \\
\hline
\end{tabular}

Panel 2: FTSE 100 Referendum

\begin{tabular}{lcccc}
\hline & Max & Min & Average & Std Dev \\
\hline Alpha & 0.0057 & -0.0067 & 0.0002 & 0.0018 \\
Beta & 3.7553 & 0.3755 & 1.0240 & 0.5278 \\
\hline
\end{tabular}


Panel 3: Currency

\begin{tabular}{lcccc}
\hline & Max & Min & Average & Std Dev \\
\hline Alpha & 0.0508 & -0.0035 & 0.0199 & 0.0167 \\
Beta & 0.0060 & -0.0724 & -0.0283 & 0.0242 \\
\hline
\end{tabular}

Table 3 shows summary outputs from all the regression parameters calculated for the market model. Average values are used for the market model assumptions.

We reviewed the results using the market model with the regression results shown in Table 3 . Average Abnormal Returns (AAR) ${ }^{2}$ were then calculated by averaging the abnormal returns for all of the days in the event period, and the Cumulative Average Abnormal Returns (CAAR) ${ }^{3}$ also calculated for several groups within the event period. Significance tests were the used for both the AARs and the CAARs to evaluate whether the abnormal results were significantly different from zero.

The tests provided T-stats and P-values for all values. These are shown in Table 4. Most of the $\mathrm{T}$ tests were insignificant but the market model delivered an AAR of -0.0126 on day 0 . These were calculated using two methods, the first uses the standard deviation of the time series of average residuals from the estimation window ${ }^{4}$ as in Kothari \& Warner (1997); the second uses the standard deviation of abnormal returns from the event window, referred to as the crosssectional method ${ }^{5}$ (Barber \& Lyon, 1997). Kothari \& Warner (1997) find that using the standard deviation of the estimation window, as in the time series method of T-stat 1, can lead to over-rejection of the null hypothesis (type one error). Barber and Lyon (1997) find a similar result suggesting that the time series method may underestimate the volatility that makes up the T-stat calculation.

Table 4.

FTSE 100 Results

Market Model

Panel 1: AAR

\begin{tabular}{cccc}
\hline Day & AAR & T-stat 1 & T-stat 2 \\
\hline \multirow{2}{*}{-3} & -0.0049 & -1.11 & -2.44 \\
& & $(0.2694)$ & $(0.0167)$ \\
-2 & $0.0058^{*}$ & 1.32 & 2.85 \\
& & $(0.1915)$ & $(0.0054)$ \\
-1 & $0.0039 *$ & 0.88 & 2.04 \\
& & $(0.3794)$ & $(0.0444)$ \\
0 & $-0.0126^{*}$ & -2.87 & -3.66 \\
& & $(0.005)$ & $(0.0004)$ \\
1 & 0.0019 & 0.44 & 1.29 \\
& & $(0.6609)$ & $(0.1993)$ \\
2 & -0.0024 & -0.54 & -1.91 \\
& & $(0.5904)$ & $(0.0595)$ \\
\hline
\end{tabular}

${ }^{2} A A R_{t}=\overline{A R_{l t}}$ the average of $A R_{i t}$, where $A R_{i t}$ is the abnormal return for firm $\mathrm{i}$ in period $\mathrm{t}$,

${ }^{3} C A A R_{t 1, t 2}=\overline{C A R_{t 1, t 2}}$ the average of all CARs, with CAR being the Cumulative abnormal return for a firm, calculated by: $C A R_{t 1, t 2}=\sum_{t 1}^{t 2} A R_{i t}$. CAR is the sum of abnormal returns from days $\mathrm{t} 1$ to $\mathrm{t} 2$ for firm $\mathrm{i}$.

${ }^{4} T-\operatorname{stat} 1(A A R)=\frac{A A R_{t}}{\sigma\left(A A R_{\text {estimation }}\right)}$ Calculated by the AAR over the standard deviation of AARs in the estimation window.

For CAARs : $T$ - stat $1(C A A R)=\frac{C_{A A R} t 1, t 2}{\sigma\left(\text { AAR }_{\text {estimation }} \sqrt{T}\right)}$ Where $\mathrm{T}$ is the number of days in the CAAR.

$5 T$ - stat $2(A A R)=\frac{A A R_{t}}{\sigma\left(A R_{t}\right)}$ Which is the $A A R_{t}$ divided by the standard deviation of abnormal returns for the period the AAR is being calculated for.

For CAARs: $T$ - stat $2(C A A R)=\frac{C A A R_{t 1, t 2}}{\sigma\left(C A R_{i t} \div \sqrt{N}\right)}$ The value of the CAAR, over the standard deviation of the CAR divided by the square root of $\mathrm{N}$, the number of firms in the sample. 


\begin{tabular}{|c|c|c|c|}
\hline \multicolumn{4}{|c|}{$\begin{array}{l}\text { Market Model } \\
\text { Panel 2: CAAR }\end{array}$} \\
\hline Day & CAAR & T-stat 1 & T-stat 2 \\
\hline$(-3,0)$ & -0.0078 & $\begin{array}{c}-0.89 \\
(0.3738)\end{array}$ & $\begin{array}{c}-1.53 \\
(0.1301)\end{array}$ \\
\hline$(-2,2)$ & -0.0034 & $\begin{array}{c}-0.35 \\
(0.7292)\end{array}$ & $\begin{array}{c}-0.72 \\
(0.4731)\end{array}$ \\
\hline$(-1,1)$ & -0.0068 & $\begin{array}{c}-0.9 \\
(0.3726)\end{array}$ & $\begin{array}{c}-1.56 \\
(0.1228)\end{array}$ \\
\hline$(0,1)$ & -0.0106 & $\begin{array}{c}-1.72 \\
(0.0883)\end{array}$ & $\begin{array}{c}-2.62 \\
(0.0103)\end{array}$ \\
\hline$(0,2)$ & $-0.0130^{*}$ & $\begin{array}{c}-1.72 \\
(0.0891)\end{array}$ & $\begin{array}{c}-3.14 \\
(0.0023)\end{array}$ \\
\hline$(1,2)$ & -0.0004 & $\begin{array}{c}-0.07 \\
(0.9437)\end{array}$ & $\begin{array}{c}-0.25 \\
(0.8064)\end{array}$ \\
\hline$(-3,2)$ & -0.0083 & $\begin{array}{c}-0.77 \\
(0.4429)\end{array}$ & $\begin{array}{c}-1.46 \\
(0.1472)\end{array}$ \\
\hline
\end{tabular}

Table 4. AAR and CAAR results for the full FTSE 100 for the November event, T-stat 1 is calculated using estimation window standard deviation, and T-stat 2 using event window standard deviation. P-values are shown in parenthesis for all t-stats. Key figures indicated by *.

When analysing just the FTSE 100, some significant results are present. Evaluating the market model as shown in Table 4, there is a significant negative deviation on AAR on day zero, with a magnitude of $1.26 \%$ significant at $95 \%$. The days following do not have any significant deviation. This is the case when looking at both T-stats (the estimation residuals and event residuals). Day -3 shows a negative significant deviation and days $-2 \&-1$ both show positive significant results. For these days they are only significant under the $2^{\text {nd }} \mathrm{T}$-stat however, providing not as strong a result as the day 0 value.

The day 0 result carries through into the event CAAR's, with periods $(0,1) \&(0,2)$ showing positive deviations significant to $95 \%$, reaching $99 \%$ significance for $(0,2)$. These results appear to be driven entirely by the movements on day 0 , with the magnitude being effectively identical for the day 0 AAR and the $(0,2)$ CAAR. The significance of the CAAR's is less robust than that of the AAR as it only appears significant when using the cross-sectional T-stat method.

In addition to the equity market analysis, a study of the foreign exchange markets was carried out to expand the reach of the study. The Brexit process has impacted substantially on the currency. A currency return was required in order to create the expected return values. Unlike with the stock market analysis, there is no market return benchmark to use here so one had to be created. This was done by averaging the returns on several currencies to create an index return, following the methods of Kwok \& Brooks (1990), who use the foreign exchange asset pricing model of Roll \& Solnik (1977).

Table 5.

Estimation and Event Window Volatility

Panel 1: Variance

\begin{tabular}{lccc}
\hline & $\mathbf{1 0 0}$ & Currency & Euro \\
\hline Estimation & 0.000367 & $2.48 \mathrm{E}-05$ & $1.27 \mathrm{E}-05$ \\
Event & 0.000481 & $9.03 \mathrm{E}-05$ & $6.48 \mathrm{E}-05$ \\
\hline & & & \\
Panel 2: Std Dev & & & \\
\hline Estimation & 0.0192 & 0.0050 & 0.0036 \\
Event & 0.0219 & 0.0095 & 0.0081 \\
\hline
\end{tabular}




\begin{tabular}{|c|c|c|c|}
\hline \multicolumn{4}{|c|}{ Panel 3: Event Window Difference } \\
\hline $\begin{array}{l}\text { Event \% } \\
\text { increase }\end{array}$ & $14.56 \% *$ & $90.73 \% *$ & $126.13 \% *$ \\
\hline \multicolumn{4}{|c|}{ Panel 4: Referendum Variance } \\
\hline Estimation & 0.0003 & $5.75 \mathrm{E}-05$ & 4.22E-05 \\
\hline Event & 0.002742 & 0.000901 & 0.000598 \\
\hline \multicolumn{4}{|c|}{ Panel 5: Referendum Std Dev } \\
\hline Estimation & 0.0173 & 0.0076 & 0.0065 \\
\hline Event & 0.0524 & 0.0300 & 0.0245 \\
\hline \multicolumn{4}{|c|}{ Panel 6: Referendum Event Window Difference } \\
\hline $\begin{array}{l}\text { Event \% } \\
\text { increase }\end{array}$ & $202.19 \% *$ & $295.79 \% *$ & $276.46 \% *$ \\
\hline
\end{tabular}

This table shows the variance for the estimation and event window for each study carried out, then takes the square root of this value to find standard deviation. Panel three shows the percentage difference in standard deviation from the estimation window to the event. Key values indicated by *.

Currency analysis presents another challenge when compared to stocks, as currency holdings will earn interest over bank holiday dates, which may create a difference in values on the following trading day. Kwok \& Brooks (1990) also investigated this and find that there is a slight change in results. As such, we conclude that it is small enough to be reasonably left out of our analysis. We present the Currency sign test in Table 6.

Table 6.

Currency Sign Test

\begin{tabular}{cccccc}
\hline Period & $\begin{array}{c}\text { Median } \\
\text { CAR }\end{array}$ & $\begin{array}{c}\text { N +ve } \\
\text { CARS }\end{array}$ & $\begin{array}{c}\text { Fraction } \\
\text { +ve }\end{array}$ & Sign Test & P-value \\
\hline$(-3,0)$ & -0.0708 & 0 & 0.30 & -1.13 & 0.3745 \\
$(-2,2)$ & -0.0585 & 0 & & -1.13 & 0.3745 \\
$(-1,1)$ & -0.0448 & 0 & & -1.13 & 0.3745 \\
$(0,1)$ & -0.0648 & 0 & & -1.13 & 0.3745 \\
$(0,2)$ & -0.0325 & 1 & & -0.13 & 0.9057 \\
$(1,2)$ & -0.1034 & 0 & & -1.13 & 0.3745 \\
$(-3,2)$ & -0.0818 & 0 & & -1.13 & 0.3745 \\
\hline
\end{tabular}

Table 6 shows the results from the currency study sign test. All CAARs used in the study are shown here. The Fraction $+v e$ column refers to the fraction of values within the estimation window which are positive.

\section{Discussion}

Our results indicate that Brexit uncertainty was not immediately priced in, as can be seen through the significance of several CAARs, most often $(0,1)$. This represents an inefficiency in capital markets. The full effect of the event takes multiple days to be fully included in prices. Theory suggests the effect should be more immediate. This further suggests that the informational transmission nature of political risk premia is different from other sources of financial risk, an important contribution in understanding the nature of capital asset pricing. We further contend that the observed uncertainty is a subset of Country risk premia and as such the speed of dissemination of political news has market importance,

Our study also provides valuable information for any country looking to undertake a similar departure from the EU. It shows the correlation between the deal outcomes and market reaction, and this reaction should be added into any cost-benefit analysis of the potential divorce process. For most other EU countries, the relationship to the EU will be different, most obviously as they are likely to be using the Euro as their currency. Therefore, the reaction of this market will be less important as there is no rate between the country and the EU. As a result, more of the 
reaction may be focused onto the domestic stock market, while potentially also impacting other domestic markets.

Our key takeaway is that events which increase the likelihood of a dramatic break in trading relationships are perceived negatively, and sectors with high levels of cross border integration are likely to be impacted. Brexit risk, as a subset of the country risk premia, can be useful in wider political risk analysis during future elections.

Improving political information dissemination would help with increasing the speed that information is included in prices. In many of the referendum and sector results, the information is not fully priced in until multiple days have passed after the event. By improving this process, prices would update more quickly, making the market more efficient.

\section{Conclusion}

We investigated the uncertainty surrounding changing sentiment to Brexit on the FTSE 100 and the Pound. Using an event study, we isolate exogenous effects on the stock and currency markets. We use adapted continuous poll data with continuous financial time series to evaluate the change in risk premia.

Our results are applicable for any major political event where opinion is divided, issue yield is low or negative and the outcome uncertain. They are relevant in such circumstances where unexpected election results or major policy shifts occur. We consider our findings useful for countries considering leaving the EU, detailing what the financial impact of this decision would be. This is because such events tend to happen in a continuum, rather than as a single event shock.

We find that a Brexit effect was evident as a subset of country risk premia. The delay in market adjustment to opinion poll changes suggests that markets are less efficient at discounting change in political sentiment than financial theory proposes.

\section{References}

Baier, S. L., \& Bergstrand, J. H. (2007). Do free trade agreements actually increase members' international trade?. Journal of international Economics, 71(1), 72-95. https://doi.org/ 10.1016/j.jinteco.2006.02.005

Binder, J. (1998). The event study methodology since 1969. Review of quantitative Finance and Accounting, 11(2), 111-137. https://doi.org/10.1023/A:1008295500105

Broby, D. (2000). Adjusting to Uncertainty, Double Takes. Goodchild, J. and Callow C. (eds) ISTE - John Wiley and Sons.

Busch, B., \& Matthes, J. (2016). Brexit-the economic impact: A meta-analysis (No. 10/2016). IW-Report.

Corrado, C. J., \& Zivney, T. L. (1992). The specification and power of the sign test in event study hypothesis tests using daily stock returns. Journal of Financial and Quantitative analysis, 465-478.

Davies, R. B., \& Studnicka, Z. (2018). The heterogeneous impact of Brexit: Early indications from the FTSE. European Economic Review, 110, 1-17.

Dhingra, S., Ottaviano, G. I., Sampson, T., \& Reenen, J. V. (2016). The consequences of Brexit for UK trade and living standards. Centre for Economic Performance. http://eprints.lse.ac.uk/id/eprint/66144 
Fama, E. F., Fisher, L., Jensen, M. C., \& Roll, R. (1969). The adjustment of stock prices to new information. International economic review, 10(1), 1-21. https://doi.org/10.2307/ $\underline{2525569}$

Hassapis, C., \& Kalyvitis, S. (2002). Investigating the links between growth and real stock price changes with empirical evidence from the G-7 economies. The Quarterly Review of Economics and Finance, 42(3), 543-575. https://doi.org/10.1016/S1062-9769(01)00111-9

Kierzenkowski, R., Pain, N., Rusticelli, E., \& Zwart, S. (2016). The economic consequences of Brexit: a taxing decision. In OECD Economic Policy Papers: OECD. https://doi.org/10.1787/5jm0lsvdkf6k-en

Kwok, C. C., \& Brooks, L. D. (1990). Examining event study methodologies in foreign exchange markets. Journal of International Business Studies, 21(2), 189-224. https://doi.org/10.1057/palgrave.jibs.8490332

Pastor, L., \& Veronesi, P. (2012). Uncertainty about government policy and stock prices. The journal of Finance, 67(4), 1219-1264. https://doi.org/10.1111/j.1540-6261.2012.01746.x

Ramiah, V., Pham, H. N., \& Moosa, I. (2017). The sectoral effects of Brexit on the British economy: early evidence from the reaction of the stock market. Applied economics, 49(26), 2508-2514. https://doi.org/10.1080/00036846.2016.1240352

Roll, R., \& Solnik, B. (1977). A pure foreign exchange asset pricing model. Journal of International Economics, 7(2), 161-179. https://doi.org/10.1016/0022-1996(77)90029-0 